\title{
WHY ENGINEER-TO-ORDER PORTFOLIO RATIONALIZATION STALLS: CHALLENGES IN STANDARDIZATION, MODULARIZATION, PLATFORM DESIGN AND MASS CUSTOMIZATION
}

\author{
C. A. Bertram ${ }^{凶}$, G. O. Mueller, M. Løkkegaard, N. H. Mortensen and L. Hvam \\ DTU-Technical University of Denmark, Denmark \\ $\triangle$ chalbe@dtu.dk
}

\begin{abstract}
There are various strategies to control complexity and variety growth in ETO businesses. Such portfolio rationalization initiatives sometimes stall. This paper elaborates on the challenges that cause this. Challenges described in literature and challenges seen in five different industry cases are consolidated. The challenges are combined into groups and presented in the ADKAR change management model. The authors intend this list to be used for guidance In industry and expect the collection to be extended with future industry cases and challenges.
\end{abstract}

Keywords: engineer-to-order, portfolio management, design strategy, variant management

\section{Introduction}

Complexity and variety is inherent in most Engineer-To-Order (ETO) businesses as the business plans are dependent on meeting new customer requirements with re-designed and re-engineered solutions. Most often it is "one-of-a-kind" production (Wortmann, 1992). A typical project-based execution means products are done project-by-project with little coordination between them (Hobday, 2000). Consequently and quite ironically, the same variety that justifies a market share, grows uncontrolled and clutters the portfolios and processes within the company. The solution space steadily grows over time and overview is blurred or lost (Fisk, 2013). As such, complexity and uncertainty do not solely arise from the product design, but also from functions of the product, especially in the interaction between the design and the processes surrounding the design (Clarkson and Eckert, 2005). Business operations have to accommodate and mitigate the growing solution space, variety and complexity, which are ultimately jeopardizing profitability (Robertson and Ulrich, 1998).

There are many motivational aspects for companies to act on this variety growth and improve control (Robertson and Ulrich, 1998). Besides the overall goal of improving profitability, there are several other benefits: Lower lead-time, better market coverage, more resources for innovation, better products and improved competitiveness (Haug et al., 2014; Wang et al., 2016). Product family design offers reduction of complexity and risk while improving development and production flexibility (Sawhney, 1998). The overall organization can also become more efficient with more effective processes (Gepp et al., 2013a, 2013b).

Various approaches (methods, tools, frameworks, etc.) have been developed for controlling such variance growth and relieving product and process cluttering (Jiao et al., 2007). Standardization 
initiatives tend to focus on canalizing projects into using selections of pre-determined components or sub-solutions. Modularization initiatives often aim at splitting solutions and systems in ways that allow exchange of sub-solutions or more specialized development of well-defined sub-systems. Platform design initiatives tend to focus on commonality across products and product-lines in order to harvest the benefits from mass-development and mass-purchase in products that are ultimately varied. Mass Customization initiatives focus on matching the uniqueness and differentiation of products with the benefits of postponed customization stages and by configurable standard solutions (Baldwin and Clark, 2006; Gepp et al., 2016).

Despite tenacious efforts, many of these initiatives fail or stall in some regard. They fail meet expectations, to secure the anticipated benefits, to make permanent improvements or simply to earn a foothold in the organization. Integration of the initiatives, especially the results, into the organization, product, processes and business is generally critical. This task can be neglected for various reasons, but can leave intended benefits vanishing (Foehr et al., 2015; Gepp et al., 2015).

The purpose of this article is to aggregate the challenges that stall portfolio rationalization initiatives in an ETO context. For this reason, challenges described in literature and challenges from industry cases are used to make one aggregated list of challenges. Section 2 outlines the Methodology for the study and the method for knowledge gathering. Section 3 presents the the main literature reviewed for challenges. Section 4 presents the aggregated challenges. Finally section 5 and 6 follows up on the meaning and significance of certain results and the value of learning from other's attempts at portfolio management.

\section{Methodology}

This section covers the methodology of the undertaken study described in this paper. The study consisted of the following three main steps:

1. Reviewing literature for challenges in ETO portfolio management

2. Supplementing the literature challenges with experienced challenges from four industry cases

3. Forming aggregated challenges from similar literature- and case-challenges

\subsection{Challenges described in literature}

When ETO companies attempt to realize the portfolio rationalization or platform development initiatives, they encounter some challenges in their progress e.g. some roadblocks that hinders progress or diminishes the benefits. Literature is reviewed to unfold possible challenges. What obstacles for the successful execution of these initiatives can be identified? What are key factors preventing initiatives from getting proper merit in the organization, producing impactful results or enabling lasting improvements?

Relevant papers were gathered by searching for various combinations of keywords. These keywords included the following: ETO, Engineer-to-order, Mass Customization, Custom*, Standardization, Standard*, Modular, Modul*, Platform, Challenges, , Problems, Roadblocks, Obstacles. However other articles were found via personal contacts, already known literature and through the references of found literature.

Papers regarding portfolio management in an ETO context were reviewed if they describe examples or challenges from attempting such initiatives. In some cases, the identified relevant papers included longer more elaborate descriptions of problematic situations. These were broken down into individual challenges as precise as possible by the authors of this paper.

\subsection{Challenges experienced in industry cases}

The experiences from portfolio rationalization projects in four industry are included in this study. Supplementary challenges are formulated from the experiences from four industry projects which were undertaken in four different ETO companies. These companies have all recently done similar portfolio management initiatives that fit within the context of this paper. The individual challenges are formulated by company contacts and researchers involved in the projects. The four cases are represented by letters A, B, C and D throughout this paper, however for the following introduction the order is randomized. 
- An inter-organization division, constructing manufacturing lines for internal production. As the products vary, so must the manufacturing lines, thus the construction projects are one-of-akind. They wish to identify how many variants they employ to similar or identical problems and to cut away unnecessary variation and standardize the best solutions.

- The company engineers processing facilities by modifying past designs to new customers requirements. They vary a handful of key functional pieces of equipment in size, configuration and numbers, to meet the requirements by specific customers. That leads to unique solutions for every order. They attempt to rationalize their portfolio by uncovering best and worst practices from historical data - an attempt to learn from past projects.

- A company that designs, manufactures and delivers highly specialized processing machinery. Their portfolio has a limited number of processing lines, yet customizations are done to every order and most elements in every line. The company wants to increase profitability by actively controlling their portfolio and discontinuing models and customizations that are unprofitable. They intend to do this by rewiring their internal processes to avoid critical customizations.

- The company wish to learn from their own history and past projects. Benefits from former best practices come from learning from own internal solutions to previously encountered requirements. This company constructs processing equipment that is sold standalone, in contrast to the others, which are part of larger facility lines.

\subsection{Aggregated challenges}

There are many similarities between the experiences in industry and the documented problems in research. To integrate as many of these as possible and to link the worlds of research and industry, aggregated challenges are formed by grouping identical or similar challenges from literature and company experiences. Thus aggregated challenges are broader and can encompass many individual challenges which all focus on the same challenging aspect of portfolio rationalization

Portfolio management can be described as a continuous effort to ensure the portfolio is optimal; ensuring efficient business processes, cost effective manufacturing, sufficient market coverage, etc. Portfolio rationalization is an intermittent activity aimed at changing (i.e. improving) the current portfolio. A popular framework model for managing changes is the ADKAR model (Galli, 2019). This model describes five mandatory steps that will help the initiative bring the desired positive change.

1. Awareness: Being aware that change is necessary or beneficial

2. Desire: Having the organizational or personal desire to do changes

3. Knowledge: Having or acquiring the information needed to perform the change

4. Ability: Being able to perform and execute the changes

5. Reinforcement: Being able to follow through with the necessary support

As the challenges described in this paper focus on portfolio rationalization as a change in the organization or business processes, it is fitting to categorize them in relation to change management. This is why these five steps will serve as categorization for the list of aggregated challenges presented in this paper.

\section{Literature}

This section presents the main literature reviewed for the study described in this paper. It contains the broader knowledge found within each source of portfolio rationalization challenges. All individual challenges are listed in the section Results

Thomassen and Alfnes (2017) focuses on the transition from ETO to Mass Customization. They do a literature review to find challenges related to this task and impose them onto a single case company as a guideline for a successful transition. The guidelines emerging from this review, are categorized into Market Interaction, Products, ICT (Information Communication Technologies), Manufacturing Technology, Processes, Manufacturing planning \& Control, Supply Chain Integration and Work Organization. Amongst others they find that: (1) Limiting the variance of offerings can compromise the business foundation. (2) Finite solution spaces are hard to define and utilize in a development environment that changes as much as ETO does. (3) Portfolio simplification risks decreased 
innovative capabilities. Furthermore there are significant challenges in the integration between processes, organizational units and the existing IT infrastructure as everything is already arranged to the freedom of ETO.

Duchi et al. (2014) reviews literature to list the main motivations of transitioning from ETO to Mass Customization. Besides the listed motivations to do so, related challenges are listed for each part of the defined ETO supply chain. To enrich the literature findings, they conduct interviews with industry representatives from four case companies. They categorize the findings in New Product Development, Sales, Order Specific Engineering, Procurement and Production \& Logistics. Challenges mainly consider working with a newly defined solution space, how to manage explicit solution knowledge and cost estimates, whether order-specific ETO designs fit a standardized sale, a new design approach and increased task automation. Knowledge and information management appears to be the biggest obstacle.

Foehr et al. (2015) presents a discussion of the role of system integration, a task sometimes neglected when ETO businesses attempt to improve their portfolio. They discuss six challenges; Integration objects, Point in time of integration, Organizational responsibility, Location of integration, Integration of rationale and Methodological support. Low quality data and poorly interconnected IT systems lead to integration challenges when dealing with information and data infrastructure. Especially when ETO products are heavily reliant on expert-knowledge, information management proves to be difficult. Additional challenges arise from internal and external cooperation, as the organization and functional units might not be set up to collaborate while intellectual property hinders information exchange needed for many partnerships. Improper change management such as poor communication and incorporation of people within the company also challenges initiative success.

Haug et al. (2009) attempts to find the correct classification and labelling of mass customizers versus ETO businesses. In that attempt, they discuss the motivations and risks of transitioning to mass customization. Amongst challenging aspects they find that a defined solution space might be inadequate to support all customer requirements and that the knowledge-based design, that characterizes ETO products, is difficult to standardize and fit within a configured business environment. It is concluded that the transition is generally "much more complex for an ETO company compared to a mass producer".

Robertson and Ulrich (1998) discuss the supporting and necessary actions for planning and implementing product platforms. They work with three distinct yet interconnected plans: (1) The product plan, (2) the differentiation plan and (3) the commonality plan. A top-management driven team must respectively plan the product launches, how they are differentiated to suit the marked needs and how elements will be shared amongst the products to optimize internal processes and sourcing. However, they also acknowledged the challenges of working across organizational units with different goals, barriers, focuses and terminology. It can be especially difficult to balance distinctiveness (offering variety) and commonality amongst a new portfolio. In this regard, company initiatives can stall if they don't engage top management, if they rely on finding "the perfect solution" compared to incremental improvements and do not work in a fact-based manner.

\section{Results}

This section presents the aggregated challenges combined from literature descriptions and the four industry case projects. The following tables present the aggregated challenges categorized according to the ADKAR model. Table 1 lists the main challenges regarding Awareness, Table 2 lists Desire-related challenges, Table 3 focuses on Knowledge, Table 4 on Ability and Table 5 on Reinforcement. The four columns with letters $\mathrm{A}, \mathrm{B}, \mathrm{C}$ and $\mathrm{D}$ represents the four industry cases. If challenges from an industry case were used to form the aggregated challenge, that case will be marked with an X.

For the interested reader or for further research, the full list of challenges within all categories are available online at a static repository (Bertram et al., 2019). The linked document contains the results in their form at the time of submission for this paper.

In order to maintain readability of the following tables, literature contributing or partly contributing to main challenges are referenced with numbers when applicable. The referenced literature is listed below each table. 
Table 1. Awareness; Being aware that change is necessary

Aggregated Challenges

\begin{tabular}{|c|c|c|c|c|}
\hline Limited knowledge of consequences for not acting & $\mathrm{X}$ & $\mathrm{X}$ & & $\mathrm{X}$ \\
\hline Limited awareness of goals and implications [1] & & & $\mathrm{X}$ & $\mathrm{X}$ \\
\hline $\begin{array}{l}\text { Potential value is not communicated clearly to all relevant stakeholders or not understood in } \\
\text { management/organization }\end{array}$ & $\mathrm{X}$ & $\mathrm{X}$ & & $\mathrm{X}$ \\
\hline Unaware of other or similar initiatives & & $\mathrm{X}$ & & \\
\hline
\end{tabular}

[1] (Duchi et al., 2014)

Table 2. Desire; Having the desire to do the change

Aggregated Challenges

\begin{tabular}{|c|c|c|c|c|}
\hline Disbelief in defined solution spaces $[1,2,3]$ & $\mathrm{X}$ & $\mathrm{X}$ & & $\mathrm{X}$ \\
\hline Disagreements on the strategy [5] & $\mathrm{X}$ & $\mathrm{X}$ & & $\mathrm{X}$ \\
\hline Resistance to change status quo & $\mathrm{X}$ & $\mathrm{X}$ & $\mathrm{X}$ & $\mathrm{X}$ \\
\hline Sub optimal scope or approach & $\mathrm{X}$ & $\mathrm{X}$ & & $\mathrm{X}$ \\
\hline The initiative is down prioritized & $\mathrm{X}$ & $\mathrm{X}$ & $\mathrm{X}$ & \\
\hline
\end{tabular}

[2] (Haug et al., 2009) [3] (Bossen et al., 2014) [4] (Schönsleben, 2012) [5] (Robertson and Ulrich, 1998)

Table 3. Knowledge; Having the necessary knowledge to undertake the change Aggregated Challenges

\begin{tabular}{|c|c|c|c|c|}
\hline Cost and lead times of a new portfolio are difficult to describe explicitly [12] & & $\mathrm{X}$ & & $\mathrm{X}$ \\
\hline $\begin{array}{l}\text { Data/Information are scattered across non-interacting IT systems and often not directly } \\
\text { usable or even obtainable }[6,7]\end{array}$ & & $\mathrm{X}$ & $\mathrm{X}$ & $\mathrm{X}$ \\
\hline $\begin{array}{l}\text { Difficult to obtain information about past sales, projects, solutions, cost and project } \\
\text { outcomes }[1,5,8,9]\end{array}$ & $\mathrm{X}$ & $\mathrm{X}$ & $\mathrm{X}$ & $\mathrm{X}$ \\
\hline Insufficient management of current portfolio & $\mathrm{X}$ & $\mathrm{X}$ & $\mathrm{X}$ & $\mathrm{X}$ \\
\hline \multicolumn{5}{|l|}{ New solutions require new knowledge [1] } \\
\hline $\begin{array}{l}\text { The product and processes are driven by knowledge which has not been systematically } \\
\text { collected }[1,2,10,11]\end{array}$ & & $\mathrm{X}$ & & $\mathrm{X}$ \\
\hline
\end{tabular}

[6] (Bohm et al., 2011) [7] (Foehr et al., 2015) [8] (Brunoe and Nielsen, 2012) [9] (Hvam et al., 2006)

[10] (Forza and Salvador, 2002) [11] (Forza and Salvador, 2006) [12] (Thomassen and Alfnes, 2017)

Table 4. Ability; Being able to do the necessary change

\begin{tabular}{|c|c|c|c|c|}
\hline Aggregated Challenges & $\mathbf{A}$ & $\mathbf{B}$ & $\mathbf{C}$ & D \\
\hline Belief that status quo is impossible to change [12] & & $\mathrm{X}$ & $\mathrm{X}$ & $\mathrm{X}$ \\
\hline Current IT solutions are not ready for new portfolio definitions $[1,12,13]$ & $\mathrm{X}$ & & & \\
\hline It is difficult to coordinate work across and beyond the organization $[1,5,6,7]$ & & $\mathrm{X}$ & & \\
\hline High variety portfolios are difficult to manage and rationalize $[2,5,12]$ & & $\mathrm{X}$ & & $\mathrm{X}$ \\
\hline Products are so unique, it is difficult to formulate a common solution space $[1,10,12,14,15]$ & $\mathrm{X}$ & $\mathrm{X}$ & $\mathrm{X}$ & \\
\hline $\begin{array}{l}\text { Rationalization will have limited effect, since business processes allow uncontrolled } \\
\text { customization }\end{array}$ & $\mathrm{X}$ & $\mathrm{X}$ & & $\mathrm{X}$ \\
\hline The initiative focus is wrong, sub optimal or too vast [5] & $\mathrm{X}$ & $\mathrm{X}$ & $\mathrm{X}$ & \\
\hline The initiative is founded at a wrong level or place in the organization & & $\mathrm{X}$ & $\mathrm{X}$ & \\
\hline The initiative leadership and/or team is not composed to properly allow decision $\mathrm{m}$ & & $\mathrm{X}$ & $\mathrm{X}$ & \\
\hline
\end{tabular}

[13] (Piller, 2004) [14] (Sabin and Weigel, 1998) [15] (Edwards et al., 2008) 
Table 5. Reinforcement; Being reinforced to follow through with the change

\begin{tabular}{l|c|c|c|c|} 
Aggregated Challenges & A & B & C & D \\
\hline Initiative results have no place to live [7,17,18,19] & & X & & \\
\hline Lack of persistent implementation effort [5,7] & & $\mathrm{X}$ & \\
\hline The initiative does not have sufficient backing in the organization [7,16] & & & \\
\hline The initiative has no place in the business structure & $\mathrm{X}$ & $\mathrm{X}$ & & \\
\hline The initiative is not driven by key decision makers & $\mathrm{X}$ & $\mathrm{X}$ & $\mathrm{X}$ & \\
\hline
\end{tabular}

[16] (Vaegs et al., 2014) [17] (Gepp et al., 2013b) [18] (Akkermans et al., 1999) [19] (Rosenman and Gero, 1998)

\section{Discussion}

There is a general agreement across the four cases on the challenges of these portfolio rationalization initiatives. Though most of the challenges from literature are represented in the case study, there are a few left. When counting the occurrences of main challenges in the cases, it is not the challenges from literature that are most present. In two instances (one in Table 3 and one in Table 5) the challenges from literature were not present in any of the included cases.

\subsection{Awareness \& desire}

From the cases it seems that unawareness of the value of acting and especially the cost of passivity are significant challenges to portfolio rationalization. It links directly to the Desire to change, as some of the frequent challenges here are the disbelief in defined solution spaces and actual resistance to change. When the value of change is not clear, then the whole point of changing is not apparent. When the point of changing is not apparent, then it feels like unnecessary actions, time and effort something that can demotivate any influenced party.

\subsection{Knowledge}

Most of the occurring challenges have a connection to the collection of data, information or knowledge. Gathering information and creating the overview of the business processes, market potentials, workflows, proper and improper solutions, routines, products and eventually impactful change potentials. That seems to be an overarching theme.

The only challenge that was encountered in all cases is the second one in Table 3: "Insufficient management of current portfolio". One of the big challenges in portfolio rationalization, is the absence of existing continuous portfolio management. Thus, the new rationalization team has to find the information, map the processes, link the dependencies, etc. with no or little foundation in previous work.

\subsection{Ability \& reinforcement}

Another common challenge appears to be to locate the right place to put the results from the rationalization project. This can also be seen the challenges about fitting new product solution spaces into the existing IT infrastructure and organizational hierarchy. The absence of existing portfolio management also expresses itself when organizations are uninteresting in changing. When the portfolio is not currently managed, why start now? This might be another reason that the lack of existing portfolio management is a frequent challenge - simply because the road has not been cleared for these discussions. In line with this, the ability to make sustained changes in the organization with lasting benefits is challenging. It seems to be a challenge to do so if there is not sufficient existing portfolio management.

The groups of challenges with most representation in the Reinforcement category concern the presence of decision makers in the team and the lack of a suited place for the resulting changes to reside. The former might provoke the latter, as an involved decision maker could also determine where the results would properly reside and make the most impact. In contrast, even though decisions can be pushed 
through, if the proper organizational residence to govern portfolio decisions is lacking, there is a large risk that any changes will vanish anyway. This is another case where existing portfolio management could be leveraged.

\subsection{Foreseeing challenges in portfolio management initiatives}

Many businesses are attempting to rationalize their portfolio and the majority of these attempts are done with similar methods. Knowledge management and knowledge sharing is still a popular subject, because it can translate directly into efficiency or savings. Hence, it is valuable to share more than success stories and share the experiences of what goes wrong.

Companies or business units undertaking the task of portfolio rationalization can screen their project environment against the presented list of challenges, in order to foresee and deal with challenges before they interfere with critical initiatives. If the organization can identify challenges as being currently present or likely to be encountered, it might be worthwhile tackling them sooner rather than later. By doing so, the list of possible challenges becomes a tool for assessing the viability of new portfolio management projects.

The authors intend this collection of challenges to evolve and be updated with more challenges and new examples of existing challenges. It would then serve as a dynamic reference list for challenges for anyone attempting similar initiatives.

\subsection{Limitations \& further work}

The authors recognize that the presented list of challenges is not exhaustive and neither was it intended to be. It is an attempt to start a long series of continuously updates to a comprehensive list of challenges. The long-term aim is for industry and researchers to share and use one reference list. Categorizing the challenges according to the ADKAR change management model, as done in this article, is just one of many ways they could be categorized. It was the conclusion of the authors that portfolio rationalization goes in parallel with change management in order to actually implement the rationales. Thus the authors found it suiting to present the results in this context.

Each of the presented challenges represents a specific problem that can be investigated and potentially mitigated or solved. In order to support companies and research groups in attempting these approaches for portfolio rationalization, it would be interesting to match them with research achievements, industry solutions and current work being undertaken. That could potentially evolve into a roadmap and troubleshooting guide for solving, mitigating or circumventing challenges that could threaten improvement initiatives.

Companies attempting to conduct portfolio improvement initiatives might do so in different scales and scopes. Some initiatives focus on commonality in the lowest level of the part-list while other initiatives aim at developing new modularized product families. This differentiation has not been accounted for when aggregating these challenges. This would be an interesting perspective to add in coming versions of this collection of challenges.

\section{Conclusion}

There are plenty of strategies and methodologies for companies to rationalize their product portfolio. However, there are as many, if not more, ways in which these initiatives can succumb to challenges so tough that the initiatives might stall or stop entirely, without securing the intended changes and benefits. This article attempts to collect and aggregate these challenges and provide industry and project groups attempting similar initiatives the possibility to tackle these challenges sooner rather than later. By knowing what others have found difficult, they might avoid or mitigate those challenges for their own journey.

State of the art literature regarding challenges in portfolio rationalization initiatives is combined with the experienced challenges in four industry case projects, to form a list of aggregated challenges. The revealed challenges are presented in categorized tables according to the ADKAR change management model with the following five steps: Awareness, Desire, Knowledge, Ability and Reinforcement. 
Amongst the identified main aggregated challenges are two pronounced themes: (1) The challenges of gathering sufficient data, information and knowledge to draw conclusions and find improvement potentials. (2) The challenges of performing portfolio rationalization when there is no or limited existing continuous portfolio management. If portfolio management is already in place, prior results and gathered information will be available and a natural starting point is established.

The presented aggregated challenges can serve as a reference for companies wanting to initiate or troubleshoot their own portfolio management projects. If they can recognize many of the challenges within their own organization, it might prove valuable to tackle those challenges before the rationalization project starts. In order to serve as a useful reference, this list must be kept relevant. It is therefore the authors' ambition that the list can be updated and extended with further research and industry cases in the future. The authors invite other researchers and practitioners to continue the supplied list of challenges.

\section{References}

Akkermans, H., Bogerd, P. and Vos, B. (1999), "Virtuous and vicious cycles on the road towards international supply chain management", International Journal of Operations \& Production Management, Vol. 19 No. 5/6, pp. 565-582. https://doi.org/10.1108/01443579910260883

Baldwin, C.Y. and Clark, K.B. (2006), "Modularity in the Design of Complex Engineering Systems", Complex Engineered Systems, Springer Berlin Heidelberg, Berlin", Heidelberg, pp. 175-205. https://doi.org/ 10.1007/3-540-32834-3_9

Bertram, C.A. et al. (2019), "ETO Challenges.xls", https://doi.org/10.11583/DTU.10732412.

Bohm, B. et al. (2011), "Mechatronic models as a driver for digital plant engineering", ETFA 2011, IEEE, pp. 18. https://doi.org/10.1109/ETFA.2011.6059100

Bossen, J. et al. (2014), “An Engineer-To-Order Mass Customization Development Framework”, IFIP Advances in Information and Communication Technology, Vol. 440, pp. 116-123. https://doi.org/10.1007/978-3-66244733-8_15

Brunoe, T.D. and Nielsen, P. (2012), “A case of cost estimation in an engineer-to-order company moving towards mass customisation”, International Journal of Mass Customisation, Vol. 4 No. 3/4, pp. 239. https://doi.org/10.1504/ijmassc.2012.047400

Clarkson, J. and Eckert, C. (2005), Design Process Improvement, Imagine.

Duchi, A. et al. (2014), "Motivations and Challeges for Engineer-to-Order Companies Moving toward Mass Customization", IFIP International Federation for Information Processing.

Edwards, K. et al. (2008), Mass Customization Services.

Fisk, D. (2013), "Engineering complexity", https://doi.org/10.1179/030801804225012617

Foehr, M., Gepp, M. and Vollmar, J. (2015), "Challenges of system integration in the engineer-to-order business", IECON 2015 - 41st Annual Conference of the IEEE Industrial Electronics Society, IEEE, pp. 7379, https://doi.org/10.1109/IECON.2015.7392078

Forza, C. and Salvador, F. (2002), "Managing for Variety in The Order Acquisition and Fulfilment Process: The Contribution of Product Configuration Systems", International Journal of Production Economics, Vol. 76 No. 1, pp. 87-98. https://doi.org/10.1016/S0925-5273(01)00157-8

Forza, C. and Salvador, F. (2006), Product Information Management for Mass Customization, Product Information Management for Mass Customization, https://doi.org/10.1057/9780230800922

Galli, B.J. (2019), “An Engineering Manager's Guide for Commonly Used Change Management Approaches”, IEEE Engineering Management Review, Vol. 47 No. 3, pp. 118-126. https://doi.org/10.1109/EMR.2019. 2896301

Gepp, M., Amberg, M. and Vollmar, J. (2013a), "Performance assessments of engineering departments: An empirical study”, IECON 2013 - 39th Annual Conference of the IEEE Industrial Electronics Society, IEEE, pp. 6934-6939, https://doi.org/10.1109/IECON.2013.6700282

Gepp, M. et al. (2013b), "Economic considerations of engineering in the industrial plant business", 2013 IEEE International Conference on Industrial Technology (ICIT), IEEE, pp. 1472-1476, https://doi.org/10.1109/ ICIT.2013.6505889

Gepp, M., Foehr, M. and Vollmar, J. (2016), "Standardization, modularization and platform approaches in the engineer-to-order business - Review and outlook", 2016 Annual IEEE Systems Conference (SysCon), IEEE, pp. 1-6, https://doi.org/10.1109/SYSCON.2016.7490549

Gepp, M. et al. (2015), "System integration in modularization and standardization programs", 2015 Annual IEEE Systems Conference (SysCon) Proceedings, IEEE, pp. 847-852, https://doi.org/10.1109/SYSCON.2015.7116856 
Haug, A., Hvam, L. and Mortensen, N.H. (2014), "Reducing variety in product solution spaces of engineer-toorder companies: the case of Novenco A/S", International Journal of Product Development, Vol. 18 No. 6 , p. 531. https://doi.org/10.1504/ijpd.2013.058556

Haug, A., Ladeby, K. and Edwards, K. (2009), "From engineer-to-order to mass customization", Management Research News, Vol. 32 No. 7, pp. 633-644. https://doi.org/10.1108/01409170910965233

Hobday, M. (2000), "The project-based organisation: an ideal form for managing complex products and systems?", Research Policy, Vol. 29 No. 7-8, pp. 871-893. https://doi.org/10.1016/S0048-7333(00)00110-4

Hvam, L., Pape, S. and Nielsen, M.K. (2006), "Improving The Quotation Process With Product Configuration", Computers in Industry, Vol. 57 No. 7, pp. 607-621. https://doi.org/10.1016/j.compind.2005.10.001

Jiao, J., Simpson, T.W. and Siddique, Z. (2007), "Product family design and platform-based product development: A state-of-the-art review", Journal of Intelligent Manufacturing, Vol. 18 No. 1, pp. 5-29. https://doi.org/10.1007/s10845-007-0003-2

Piller, F.T. (2004), "Mass Customization: Reflections On The State of The Concept", International Journal of Flexible Manufacturing Systems, Vol. 16 No. 4 SPEC. ISS, pp. 313-334. https://doi.org/10.1007/s10696005-5170-x

Robertson, D. and Ulrich, K. (1998), "Planning for Product Platforms", Sloan Management Review, Vol. 39 No. 4, pp. 19-31, DOI:Article.

Rosenman, M.A. and Gero, J.S. (1998), "Purpose and Function in Design: From the Socio-Cultural to The Technophysical”, Design Studies, Vol. 19 No. 2, pp. 161-186. https://doi.org/10.1016/S0142694X(97)00033-1

Sabin, D. and Weigel, R. (1998), "Product configuration frameworks - A survey", IEEE Intelligent Systems and Their Applications, Vol. 13 No. 4, pp. 42-49. https://doi.org/10.1109/5254.708432

Sawhney, M.S. (1998), "Leveraged High-Variety Strategies : to Platform Thinking”, Journal of the Academy of Marketing Science, Vol. 26 No. 1, pp. 54-61.

Schönsleben, P. (2012), "Methods and Tools That Support a Fast and Efficient Design-to-Order Process for Parameterized Product Families”, CIRP Annals - Manufacturing Technology, Vol. 61 No. 1, pp. 179-182. https://doi.org/10.1016/j.cirp.2012.03.071

Thomassen, M.K. and Alfnes, E. (2017), "Mass Customization Challenges of Engineer-to-Order Manufacturing”, Springer, Cham, pp. 27-39, https://doi.org/10.1007/978-3-319-29058-4_3

Vaegs, T. et al. (2014), "Fostering interdisciplinary integration in engineering management", IEEE International Conference on Industrial Engineering and Engineering Management, pp. 23-28. https://doi.org/10.1109/ IEEM.2013.6962367

Wang, Z. et al. (2016), "Effects of standardization and innovation on mass customization: An empirical investigation", Technovation, Vol. 48-49, pp. 79-86. https://doi.org/10.1016/j.technovation.2016.01.003, Elsevier.

Wortmann, J.C. (1992), "Production management systems for one-of-a-kind products", Computers in Industry, Vol. 19 No. 1, pp. 79-88. https://doi.org/10.1016/0166-3615(92)90008-B 
